\title{
Erratum to: Counting number fields in fibers (with an Appendix by Jean Gillibert)
}

Yuri Bilu ${ }^{1}$

Published online: 19 June 2017

(C) Springer-Verlag GmbH Deutschland 2017

\section{Erratum to: Math. Z. DOI 10.1007/s00209-017-1900-5}

In the original publication, the author of the appendix section has been included as a co-author of the article inadvertently. Hence, the author group is corrected with this erratum. Further, the article title has been updated as given below:

Counting number fields in fibers (with an Appendix by Jean Gillibert)

The original article has been corrected.

The online version of the original article can be found under doi:10.1007/s00209-017-1900-5.

Yuri Bilu

yuri@math.u-bordeaux.fr

1 Institut de Mathématiques de Bordeaux, Université de Bordeaux et CNRS, Talence, France 